\title{
Antimicrobial Activity in the Marine Cheilostome Bryozoan Cryptosula zavjalovensis Kubanin, 1976
}

\section{Quaiyum $\mathbf{S}^{1^{*}}$, Fortunato $\mathrm{H}^{2}$, Gonzaga $\mathrm{LJ}^{3}$ and Okabe $\mathrm{S}^{4}$}

${ }^{1}$ Division of Applied Bioscience, Faculty of Agriculture, Hokkaido University, Sapporo, Japan

${ }^{2}$ Department Natural History Sciences, Faculty of Science, Hokkaido University, Sapporo, Japan

${ }^{3}$ Faculty of Sciences and Technology, University of Algarve, Faro, Portugal

${ }^{4}$ Department of Environmental Engineering, Graduate School of Engineering, Hokkaido University, Sapporo, Japan

*Corresponding author: Quaiyum S, Division of Applied Bioscience, Faculty of Agriculture, Hokkaido University, Sapporo 060-0810, Japan, Tel: +81 080 9003 6898; Email: megh1710@gmail.com

Received date: August 08, 2018; Accepted date: August 20, 2018; Published date: August 27, 2018

Copyright: $\odot 2018$ Quaiyum S, et al. This is an open-access article distributed under the terms of the Creative Commons Attribution License, which permits unrestricted use, distribution, and reproduction in any medium, provided the original author and source are credited.

\begin{abstract}
Objectives: The ecological function and the antibacterial activity of the marine Bryozoan (Cryptosula zavjalovensis) from the north Pacific have remained unknown. C. zavjalovensis produced a strong odor when it alive and can survive on the upper side of substrates, implying strong competition ability as well as the presence of possible antibacterial activity. The aim of the study is to investigate the antibacterial activity of the $C$. zavjalovensis on 11 laboratory pathogenic (Gram positive and Gram negative) bacteria.
\end{abstract}

Methods: To investigate the antibacterial activity, specimens were collected at Akkeshi (Japan) was used to obtain water and methanol extracts which were then tested against 11 laboratory stoke bacterial strains. The presence of biological activity in the extracts was detected through the agar well diffusion method by measuring the zone of inhibition (ZOI) on the tested microorganisms.

Results: Results from the bioassays reveal that both extracts exhibited relatively strong antibacterial activity against most of the bacterial strains tested. This is the first test for antibacterial activity done with the Bryozoan $C$. zavjalovensis. The broad spectrum of antibacterial activity detected in the study shows that the active metabolites of this organism could potentially be used against common bacteria such as (Bacillus spp.) and (Enterobacter spp.) which cause several food borne diseases and can develop resistant spores.

Conclusion: Thus, C. zavjalovensis could be a source of important compounds targeting pathogenic organisms. However, before any possible practical testing including possibly clinical trials, it is necessary to isolate the bioactive substance and determine its exact mechanism of action.

Keywords: Anti-fouling; Antibacterial; Chemical defenses; Mechanism of action; Metabolites; Bioactive compounds

\section{Introduction}

In the marine environment, most of the surfaces of marine animals are usually colonized by sessile organisms (epibionts) such as diatoms, bacteria, protozoa, algae and other invertebrates, which cause fouling [1]. However the surfaces of many of these animals remain free of those epibionts or surface microorganisms are inhibited by secondary metabolites produced by the animal due to adaptation to prevent fouling. Possible antifouling mechanisms include mechanical, physical and chemical defenses. Bioactive compounds are often used alone or combined to inhibit bacterial growth and as such they could eventually be exploited in pharmacology [2].

Bryozoans are a phylum of aquatic, colonial sessile, filter-feeding marine invertebrates that frequently host communities of microorganisms and small invertebrates within their colony structures and may produce active substances used as chemical protection against possible harmful epibionts [3-9]. Although the phylum Bryozoan contains several thousand species, studies on natural products and its use as chemical defenses have focused only on a few of them and Bryozoan metabolites account only for about $1 \%$ of marine natural products, according to recent reviews [10,11].

C. zavjalovensis Kubanin 1976 is a marine cheilostome Bryozoan widely distributed and patchily abundant intertidally on rocky shores around the North Pacific rim, from Ketchikan in southeastern Alaska to northern Honshu in Japan [12-14]. It is bright yellow to orange in color and produces a strong, pungent odor when alive (Figure 1) [12]. Whereas most rocky-intertidal Bryozoans inhabit cryptic microhabitats under boulders and in crevices, $C$. zavjalovensis frequently encrusts exposed hard substrates, and its colonies are often scarcely fouled leading to speculation that the odor-producing compound (or some other substance) might inhibit larvae from other organisms from settling on the colony and/or by interfering with the surficial bacterial film that is, might have antibacterial activity.

In this study, we investigated the antibacterial activity of water and methanol extracts from C. zavjalovensis against a diverse array of bacterial strains from laboratory culture collections on the basis of their field observation. 
A

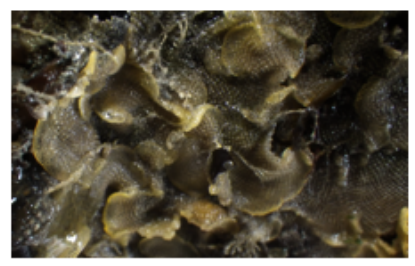

$\mathrm{C}$
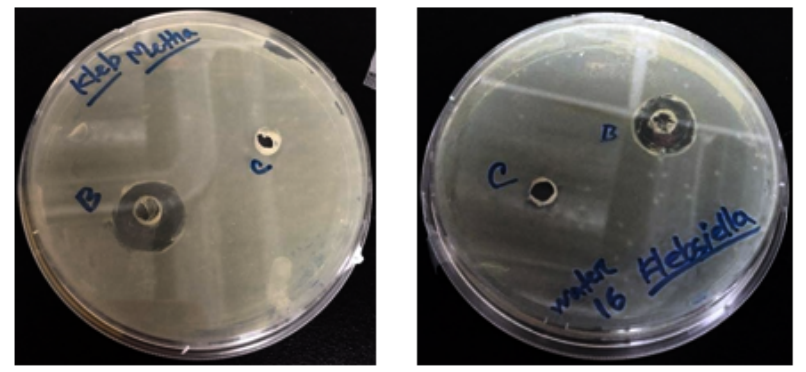

Figure 1: A) Cryptosula zavjalovensis field picture. B) Scanning electron microscope photograph of $C$. zavjalovensis. C) Agar plate showing the zone of inhibition of methanol extracts in a Klebsiella spp. SqK01 culture well. D) Agar plate showing the zone of inhibition of water extracts in a Klebsiella spp. SqK01 culture well. (In $\mathrm{C}$ and $\mathrm{D}$ panels: $\mathrm{B}=$ well with the tested microorganisms and the ryozoan extract; $\mathrm{C}=$ well used as control).

\section{Materials and Methods}

\section{Specimen collection and processing}

C. zavjalovensis was collected by hand in the intertidal zone at low tide in June 2016 from the pier and rock of the Akkeshi Marine Biological Station $\left(43^{\circ} 01.03^{\prime} \mathrm{N}, 144^{\circ} 50.26^{\prime} \mathrm{E}\right)$, eastern Hokkaido of Japan. Five replicate samples were taken each one consisting of parts of one or more colonies scraped from rocks or concrete substrates. Samples were transported to the Akkeshi Marine station where they were kept in running seawater at ambient temperature until they were processed. Colonies were identified under a stereomicroscope and then cleaned with distilled water before further processing [12].

\section{Preparation of water and methanol extraction for antibacterial activity assessments}

Fresh colonies were pulverized with a mortar and $135 \mathrm{ml}$ deionized water were mixed with $15 \mathrm{~g}$ of each pulverized sample, which is considered as the water extracts (9: 1 weight ratio) in this study. For the methanol extracts, samples were preserved in ethanol after rinsing with distilled water. To obtain a crude extract, the samples were first homogenized and dried and the dried extract added to a mixture of water and ethyl acetate. The soluble components in the crude extract were dissolved into the organic (ethyl acetate) and aqueous phases, which were then separated by using solid phase extraction methods, and then dried to obtain the ethyl acetate and water fractions. The water fraction was separated from the methanol one and the liquid phase of methanol was used for antibacterial activity testing [15].

\section{Assay for antimicrobial activity}

Pulverized whole colonies (water extracts) and methanol extracts of C. zavjalovensis were assessed for antimicrobial activity using the agarwell diffusion method and the following bacterial strains: Shigella spp. SkS01, E. coli SkE01, Salmonella spp. SkS02, Xanthomonas spp. A9, Klebsiella spp. SqK01, Bacillus spp. A10, Enterobacteria spp. A27, Pseudomonas spp. A30, Actinobacter spp. A37, Staphylococcus spp. SkS02, and Vibrio spp. SkV01 [16]. For each strain a pure laboratory culture was used to inoculate $2 \mathrm{ml}$ of Mueller Hinton broth medium (Oxford Ltd., Basingstoke, Hampshire, England) and the culture incubated for 24 hours at $37^{\circ} \mathrm{C}$.

All sterile broth bacterial suspensions were adjusted to a density of $106 \mathrm{cfu} / \mathrm{ml}^{-1}$ (colony forming units per $\mathrm{ml}$ ) equivalent to the turbidity of a $0.5 \mathrm{McFarland}$ standard. For each microorganism, one sterile cotton swab was used to obtain an amount of the bacterial broth suspension that was then spread onto a plastic $8 \mathrm{~cm}$ Petri dish containing Mueller-Hinton agar medium to provide a bacterial lawn and allowed to dry for 10 minutes.

After the bacterial lawn was fully absorbed, two wells (diameter 6 $\mathrm{mm}$ and volume $8 \mathrm{~mm}^{3}$ ) spaced $2.6 \mathrm{~cm}$ apart were prepared by using a sterile pipette separately for each, one for the Bryozoan extract to be tested and the other for the negative control. For each assay, $100 \mu \mathrm{L}$ of each extract was pipetted into the test well, and $100 \mu \mathrm{L}$ of distilled water (for assays of water extracts) or $100 \mu \mathrm{L}$ of $30 \%$ methanol in distilled water (for assays of methanol extracts) into the control well. After absorption of the test and control volumes into the wells, plates were incubated for 24 hours at $37^{\circ} \mathrm{C}$.

After incubation, the diameter of the clear zone surrounding each well (zone of inhibition, or ZOI), including the diameter of the well, was measured as the degree of bacterial inhibition, or antimicrobial activity. Experiments of whole pulverized colonies (Water extracts) were done in five replicates and experiments of methanol extracts were done in fifteen replicates. Mean ZOIs greater than $15 \mathrm{~mm}$ were considered as having strong antimicrobial activity as in previous studies [17-19].

\section{Statistical analysis}

All measurements were entered in Excel and then a single factorial analysis of variance (ANOVA) was used to test the two types of extracts (water and methanol) against specific bacterial strains. Values of $\mathrm{P}<0.05$ were taken as significant [20].

\section{Results}

Antimicrobial activity was tested against 11 bacterial strains using water and methanol extracts from C. zavjalovensis collected at Akkeshi Marine Biological Station.

The zones of inhibition (ZOI) for both extracts against the tested organisms are given in Table 1. 
Page 3 of 5

\begin{tabular}{|c|c|c|c|c|c|c|c|}
\hline \multirow{2}{*}{ Name of bacterial strain } & \multicolumn{3}{|c|}{ Water extract ZOI $(n=5)$ in $\mathrm{mm}$} & \multicolumn{3}{|c|}{ Methanol extract $\mathrm{ZOI}(\mathrm{n}=5)$ in $\mathrm{mm}$} & \multirow[t]{2}{*}{ Single factor ANOVA $F$ value } \\
\hline & Mean \pm SD & Minimum & Maximum & Mean \pm SD & Minimum & Maximum & \\
\hline Staphylococcus spp. SkS02 & $15.31 \pm 0.31$ & 15.29 & 15.34 & $16.92 \pm 2.65$ & 12.95 & 19.47 & 0.19748 \\
\hline Actinobacter spp. A37 & $18.13 \pm 0.36$ & 18.11 & 18.16 & $14.23 \pm 1.66$ & 12.87 & 16.98 & $0.00007^{*}$ \\
\hline Bacillus spp. A10 & $15.13 \pm 0.22$ & 15.11 & 15.16 & $20.83 \pm 1.35$ & 19.35 & 22.89 & $0.00113^{*}$ \\
\hline Klebsiella spp. SqK01 & $14.70 \pm 0.58$ & 14.68 & 14.73 & $17.15 \pm 1.39$ & 15 & 18.27 & $0.00113^{*}$ \\
\hline Xanthomonas spp. A9 & $12.70 \pm 0.26$ & 12.68 & 12.73 & $16.18 \pm 2.03$ & 13.64 & 18.48 & $0.00144^{*}$ \\
\hline Shigella spp. SkS01 & $18.40 \pm 0.15$ & 18.38 & 18.43 & $18.70 \pm 1.21$ & 16.9 & 20.24 & 0.59033 \\
\hline Enterobacteria spp. A27 & $14.82 \pm 1.31$ & 14.8 & 14.85 & $20.26 \pm 1.36$ & 18.25 & 21.45 & $0.00006^{*}$ \\
\hline Pseudomonas spp. A30 & $16.17 \pm 0.75$ & 16.15 & 16.2 & $18.63 \pm 0.73$ & 17.83 & 19.88 & $0.01345^{*}$ \\
\hline E. coli SkE01 & $16.17 \pm 0.95$ & 18.31 & 18.6 & $14.95 \pm 2.71$ & 11.1 & 18 & $0.01345^{*}$ \\
\hline Salmonella spp. SkS02 & $19.80 \pm 0.86$ & 19.78 & 19.83 & $14.69 \pm 0.74$ & 13.81 & 15.66 & $0.00001^{* *}$ \\
\hline Vibrio spp. SkV01 & $16.25 \pm 0.711$ & 16.23 & 16.28 & $19.31 \pm 1.15$ & 17.79 & 20.77 & 0.00001 \\
\hline
\end{tabular}

Table 1: Mean, minimum and maximum value of the zone of inhibition (ZOI) of Cryptosula zavjalovensis on 11 tested bacterial strains using the whole colonies pulverized in deionized water (water extracts) and methanol extracts. The single factor ANOVA presents the significant differences between water and methanol extracts $(\mathrm{P}<0.05)$.

The highest zone of inhibition for the water extract tests was found against Salmonella spp. SkS02 (ZOI=19.80 mm) and the lowest $(\mathrm{ZOI}=12.70 \mathrm{~mm})$ for Xanthomonas spp. A9 (Table 1). Except in tests of Enterobacteria spp. A27, Xanthomonas spp. A9, Klebsiella spp. SqK01, all other zones of inhibition were $>15 \mathrm{~mm}$ (Table 1). On the other hand, among the methanol extract probes the highest zone of inhibition $(\mathrm{ZOI}=20.83 \mathrm{~mm})$ was found against Bacillus spp. A10 and the lowest $(\mathrm{ZOI}=14.23 \mathrm{~mm})$ against Actinobacter spp. A37. Except for Actinobacter spp. A37, E. coli SkE01 and Salmonella spp. SkS02, all zones of inhibition were $>15 \mathrm{~mm}$ (Table 1). None of the control wells in any of the assays showed signs of a zone of inhibition (no clear zone around the well could be observed). Among all, the ZOI between two extracts against Shigella spp. SkS01 (0.59033) and Staphylococcus spp. SkS02 (0.19748) were not significantly different at $\mathrm{P}<0.05$.

\section{Conclusion}

The bioassay results revealed that both extracts exhibited strong antimicrobial activity showing zones of inhibition $>15 \mathrm{~mm}$ in most of the tests. Nevertheless, in all cases the zones of inhibition for both extracts varied significantly (Table 1) which could be due to the solubility of the possible bioactive compounds in the different solvents used.

Significant discussions exist about the use of zones of inhibition and what size can be considered representative. Bergquist and Bedford ignored all zones of inhibition less than $1 \mathrm{~mm}$ wide, whereas Lippert et al. regarded extracts as possessing antibacterial activity or strong inhibition if the ZOI was $>7-15 \mathrm{~mm}[21,18]$. Other authors have considered any zone of inhibition as an indication of antimicrobial activity independently of its size [17,22]. The present study considers ZOI of any size as positive since the diameter of the zone is partially related to the ability of metabolites to diffuse through the agar, and lipid-soluble compounds will often diffuse less well than more polar ones [9]. However, these matters have to be considered with more concern since the diffusion rate of some antibacterial compounds could probably affect the size of the inhibition zone too. Besides, physical and chemical characteristics of the extracts such as viscosity or $\mathrm{pH}$ could inhibit the growth of bacteria and primary metabolites could even exhibit weak inhibitory effects when tested at high concentrations $[23,24]$. In this study, both extracts exhibited clear inhibition zones against all tested bacterial strains (Table 1). To our knowledge, this is the first time that antibacterial activity is reported for C. zavjalovensis.

The present study was conducted with specimens collected from Akkeshi, Hokkaido, Japan. In order to make definitive conclusions about the ecological function of these metabolites it is necessary to test specimens from other areas of the species distribution. Differences in antimicrobial activity within populations of the same species have been shown previously [18]. In one study, it was reported that (Flustra foliacea) from the North Sea produced flustramine E 68 with antimicrobial activity against Bacillus subtilis, while $F$. foliacea from a different area (Canada) did not show any antibacterial activity [17]. Besides, the presence of chemicals can vary with different depths. For example, two distinct chemo types have been found within Bugula neritina populations at the same location but at different depths [25].

Bacteria used for this experiment were collected from laboratory stock cultures. Different strains of these same bacterial groups can come into contact with $C$. zavjalovensis in nature. Unfortunately, little is known about this Bryozoan ecology, so field tests are needed to see how the same bacterial groups affect the Bryozoan in natural conditions and how its metabolites eventually are used for defense in order to better understand the obtained laboratory results. Besides, it has been shown that antibacterial activity against non-marine 
pathogenic bacteria does not necessarily indicate the same activity exists against marine bacteria [21]. As discussed by Jenkins et al. ecologically sensible bioassays have to involve the use of microorganisms that interact with the investigated organism in nature. This study's aim was to test the existence of antibacterial activity of $C$. zavjalovensis using laboratory grown microorganisms and its possible use by the organisms. Further tests should be done in the field to confirm the results.

An important point to take into attention is that in some cases the metabolites isolated from Bryozoans are not actually Bryozoan in origin. Such is the case of bryostatin, important bioactive compounds produced by symbiotic bacteria associated with the Bryozoan Bugula neritina [25]. It is worth pointing out that we cannot exclude the possibility of symbiotic microorganisms being the source of the active compound observed in our tests. So, future studies of $C$. zavjalovensis metabolites also need to verify which organism produces it, the Bryozoan or an associated symbiont. In addition, the different responses of the studied microorganisms towards methanol and the water extracts might be due to other reasons such as the different concentrations of water and methanol used and that could explain some of the differences between the zones of inhibition found.

\section{Conclusion}

Nowadays, antibiotic resistance is becoming one of the major problems in medicine. The increase of pathogenic microbes with multiple resistance mechanisms considerably reduced the effectiveness of conventional commercial drugs. Hence, there is a constant need for new drugs with novel mechanisms of action. The evolution of antibiotic-resistant bacteria has also stimulated the search for potential antibacterial agents from natural sources [26-28]. The antibacterial activity detected in this Bryozoan could potentially be used against common bacteria such as Bacillus spp. and Enterobacter spp. which cause several food borne diseases and can develop resistant spores $[29,30]$. Thus, $C$. zavjalovensis could be a source of important antibacterial compounds. However, before any possible practical testing, it is necessary to determine the exact mechanism of action, isolate the compounds and then follow with practical tests.

\section{Acknowledgement}

We are thankful to Dr. Takefumi Yorisue and the lab members of Akkeshi marine biological station who helped during sampling. Dr. M. H. Dick helped to improve the manuscript. Our thanks are due to all lab members and researchers of the Biodiversity 1 laboratory and the members of the water quality control engineering laboratory of Hokkaido University for their support during this study.

\section{Funding}

This work was funded by an Erasmus Mundus scholarship under the Erasmus Mundus Master in Chemical Innovation and Regulation (EMMC ChIR) Program and a partial scholarship from the Japanese Government (MEXT) Super Global University Project.

\section{References}

1. Heindl H, Thiel V, Wiese J, Imhoff JF (2012) Bacterial isolates from the Bryozoan Membranipora membranacea: Influence of culture media on isolation and antimicrobial activity. Int Microbiol 15: 17-32.
2. Pejin B, Glamoclija JM, Ciric A, Sokovic M (2012) Antimicrobial activity of freshwater Bryozoan Hyalinella punctata (Hancock, 1850). Digiest J Nan Bio 7: 1021-1026.

3. Peters L, Konig GM, Wright AD, Pukall R, Stackebrandt E, et al. (2003) Secondary metabolites of Flustra foliacea and their influence on bacteria. Appl Env Micr 69: 3469-3475.

4. Ananthan G, Hussain SM, Sivaperumal P, Jaffar A (2011) Screening for novel drug properties from marine tunicate against human urinary tract pathogens. J Phar Res 4: 356-357.

5. Gerdes G, Kahle J, Wieking G, Liebezeit G, Scholz J (2005) Bryozoen kontrollieren ihre biofilme. "gepflegte" mikrogarten auf belebter oberflache. Biol Unse Zeit 35: 250-259.

6. Hadfield MG, Paul VJ (2001) Natural chemical cues for settlement and metamorphosis of marine invertebrate larvae. Mar Chem Ecol 13: 431-61.

7. Hadfield MG (2011) Biofilms and marine invertebrate larvae: What bacteria produce that larvae use to choose settlement sites. Ann Rev of Mar Sci 3: 453-470.

8. Ryland JS (2005) Bryozoa: An Introductory Overview. Denisia 16: 9-20.

9. Walls JT, Ritz DA, Blackman AJ (1993) Fouling surface bacteria and antibacterial agents of four Bryozoan species found in Tasmania, Australia. J Exp Mar Biol Ecol 169: 1-13.

10. Blunt JW, Copp BR, Munro MH, Northcote PT, Prinsep MR (2010) Marine natural products. Nat Prod Rep 27: 160-258.

11. Sharp JH, Winson MK, Porter JS (2007) Bryozoan metabolites: An ecological perspective. Nat Pro Rep 24: 659-673.

12. Dick MH, Grischenko AV, Mawatari SF (2005) Intertidal Bryozoa (Cheilostomata) of Ketchikan, Alaska. J Nat Hist 39: 3687-3784.

13. Grischenko AV, Dick MH, Mawatari SF (2007) Diversity and taxonomy of intertidal Bryozoa (Cheilostomata) at Akkeshi Bay, Hokkaido, Japan. J Nat His 41: 1047-1161.

14. Kubanin AA (1976) Intertidal Bryozoa of Zav'yalov Island (Sea of Okhotsk). J Mar Biol 1: 30-35.

15. Lopez JAV, Lihaibi SSA, Alarif WM, Lateff AA, Nogata Y, et al. (2016) Wewakazole B, a cytotoxic cyanobactin from the cyanobacterium Moorea producens collected in the Red Sea. J Nat Prod 79: 1213-1218.

16. Balouiri M, Sadiki M, Ibnsouda SK (2016) Methods for in vitro evaluating antimicrobial activity: A review. J Phar Anal 6: 71-79.

17. Figuerola B, Comorera LS, Preckler CA, Vazquez J, Montes MJ, et al. (2014) Antimicrobial activity of antarctic Bryozoans: An ecological perspective with potential for clinical application. Mar Environ Res 101: 52-59.

18. Lippert H, Brinkmeyer R, Mulhaupt T, Iken K (2003) Antimicrobial activity in sub-Arctic marine invertebrates. Pol Biol 26: 591-600.

19. Suresh M, Arularasan S, Kumaran SN (2012) Screening on antibacterial activity of marine gastropods Babylonia zeylanica (Bruguitere, 1789) and Harpa conoidalis (Lamarck, 1822) from Mudasalodai, southeast coast of India. Int J Phar Pharma Sci 4: 552-556.

20. Howell DC (2002) Statistical methods for psychology. Duxbury. National Library of Australia.

21. Bergquist PR, Bedford JJ (1978) The incidence of antibacterial activity in marine Demospongiae, Systematic and geographical considerations. Mari Biol 46: 215-221.

22. Kelman D, Kashman Y, Rosenberg E, Ilan M, Ifrach I, et al (2001) Antimicrobial activity of the reef sponge Amphimedon viridis from the Red Sea: Evidence for selective toxicity. Aqu Micr Eco 24: 9-16.

23. Jenkins KM, Jensen PR, Fenical W (1998) Bioassays with marine microorganisms. Meth Chem Ecol 2: 1-3.

24. Jensen PR, Harvell CD, Wirtz K, Fenical W (1996) Antimicrobial activity of extracts of Caribbean gorgonian corals. Mar Bio 125: 411-419.

25. McGovern TM, Hellberg ME (2003) Cryptic species, cryptic endosymbionts and geographical variation in chemical defenses in the Bryozoan Bugula neritina. Mol Ecol 12: 1207-1215.

26. Prinsep MR, Yao B, Nicholson BK, Gordon DP (2004) The pterocellins, bioactive alkaloids from the marine Bryozoan Pterocella vesiculosa. Phytochem Rev 3: 325. 
Citation: Quaiyum S, Fortunato H, Gonzaga LJ, Okabe S (2018) Antimicrobial Activity in the Marine Cheilostome Bryozoan Cryptosula zavjalovensis Kubanin, 1976. J Antimicrob Agents 4: 178. doi:10.4172/2472-1212.1000178

Page 5 of 5

27. Blunt JW, Copp BR, Hu WP, Munro MHG, Northcote PT, et al. (2007) Marine Natural Products. Nat Prod Rep 24: 31-86.

28. Tharmalingam N, Rajmuthiah R, Kim W, Fuchs BB, Jeyamani E, et al. (2018) Antibacterial properties of four novel hit compounds from a methicillin-resistant Staphylococcus aureus-Caenorhabditis elegans highthroughput screen. Microb Drug Resist 24: 666-674.

29. Fischer AR, De JAE, van AED, de JR, Frewer LJ, et al. (2007) Food safety in the domestic environment: An interdisciplinary investigation of microbial hazards during food preparation. Risk Anal 27: 1065-1082.
30. Ghelardi E, Celandroni F, Salvetti S, Barsotti C, Baggiani A, et al. (2002) Identification and characterization of toxigenic Bacillus cereus isolates responsible for two food-poisoning outbreaks. FEMS Micrbiol Lett 208: 129-134. 